\title{
Papers
}

\section{Adherence to advance directives in critical care decision making: vignette study}

Trevor Thompson, Rosaline Barbour, Lisa Schwartz

\begin{abstract}
Objective To explore health professionals' decision making in a critical care scenario when there is an advance directive.

Design Qualitative study.

Setting Scotland.

Participants Interviewees $(\mathrm{n}=12)$ comprising general practitioners, hospital specialists, and nurses, and six focus groups ( $\mathrm{n}=34$ participants) comprising general practitioners, geriatricians (consultants and specialist registrars), hospital nurses, and hospice nurses.

Results When presented with an advance directive that applied to the same hypothetical scenario, health professionals came to divergent conclusions as to the "right thing to do." Arguments opposing treatment centred on the supremacy of autonomy as an ethical principle. Other arguments were that the decision to treat was consistent with the terms of the advance directive, or that, notwithstanding the advance directive, the patient's quality of life was sufficient to warrant treatment.

Conclusion Advance directives are open to widely varying interpretation. Some of this variability is related to the ambiguity of the directive's terminology whereas some is related to the willingness of health professionals to make subjective value judgments concerning quality of life.
\end{abstract}

\section{Introduction}

Decisions to withhold or withdraw life prolonging treatments are among the most difficult to make for patients and health professionals. ${ }^{1}$ Paternalism has widely been replaced by an emphasis on patient participation, respect for autonomy, and quality of life and death. ${ }^{2-4}$ Although the need to integrate the perspectives of patients, relatives, and other carers into decision making poses new challenges for clinicians, it is not known to what extent this happens in practice.

Particular difficulties arise when a critically ill patient is cognitively impaired. Here the health professionals and relatives engage in "soft" paternalism, making decisions in the best interests of the incapacitated patient. ${ }^{5}$ The premorbid verbal testimony of the patient can be included, with the lay carer acting as a healthcare "proxy."

It is in this context that the advance directive is cited as a means of promoting patient autonomy-providing a written statement of treatment preferences made when the patient was in sound mind. But do these documents really uphold the stated preferences of the now incapacitated patient? One prospective study showed that in most cases advanced directives were not consulted by carers in critical care situations. ${ }^{7}$

Work from the United States has shown that advance directives have no effect in improving the accuracy of substituted judgments by proxies (friends or relatives) ${ }^{8}$ No equivalent studies have specifically examined the effect of advance directives on health professionals' decision making, although there is work on their views and experiences. ${ }^{9}{ }^{10}$ When faced with an advance directive in a critical care scenario what decisions are made and how are these justified?

To approach this question we elicited health professionals' responses to a critical care vignette of a fictitious patient who had previously signed an advance directive (box 1). The vignette was constructed to highlight the ethical dilemmas that arise when implementing advance directives in the clinical setting.

\section{Methods}

Data were generated through a combination of individual interviews and focus groups. Our purposive sample was defined for three primary dimensions. The first was the professional group, as, for example, nurses, are more likely to assume the role of patient advocate, with doctors often in the role of decision maker. ${ }^{11}$ The second was experience with the implementation of advance directives, as we wanted to include participants for whom the advance directive was more than a theoretical construct. The third was attitude to advance directives, as we wanted to include a wide range of perspectives.

The quota for the prospectively defined sample was met through a variety of established methods, including the use of "key informants." For instance, information from a campaigner for voluntary euthanasia led to the inclusion of two participants who had opposed each other in a public debate. We conducted 12 interviews and six focus groups. The focus groups comprised consultants and specialist registrars in medicine for elderly people, nurses, general practitioners, and hospice staff. Tables 1 and 2 show the characteristics of the participants.

Participants were provided with a hypothetical advance directive, constructed after analysis of three
Division of Primary Health Care,

University of

Bristol, Bristol BS6 6JL

Trevor Thompson clinical lecturer

School of Nursing and Midwifery,

University of

Dundee, Dundee

DD1 4HJ

Rosaline Barbour professor of health and social care

Department of

Clinical

Epidemiology and

Biostatistics,

McMaster

University, 1200

Main Street West

Hamilton Ontario,

Canada L8N 3Z5

Lisa Schwartz

professor of health

care ethics

Correspondence to:

$\mathrm{T}$ Thompson

trevor.thompson@

bristol.ac.uk

bmj.com 2003;327:1011 


\section{Box 1: Hypothetical advance directive}

To my doctors, health care team, family, and other persons concerned Name: Patient

Address: Flat 2, Any Street, Any Town, Scotland

After careful consideration and discussion with my medical advisers I have freely and in sound mind decided that it is my express wish that if I should develop:

- Severe degenerative brain disease (due to Alzheimer's disease, arterial disease, or other agency)

- Serious brain damage as a result of stroke, injury, or other illness

- Advanced terminal malignancy

- Severely incapacitating disease of nerve or muscle

- Any other condition of comparable gravity

and as a result suffer mental impairment such that I am unable to participate in decisions regarding my care, and two independent physicians conclude that to the best of their knowledge my underlying condition is irreversible, then the following points should be taken into consideration: - In the event of cardiac arrest, regardless of the cause, I should not be given cardiopulmonary resuscitation

- With the development of any life threatening medical situation I should not be given active treatment such as antibiotics, ventilation, surgery, or blood transfusion

- Any futile treatment initiated out with terms of this directive should be withdrawn

- If during an advanced illness I should become unable to swallow food, fluid, or medication then these should not be given to me by drip or feeding tube into intestines or vein

- I wish to have ordinary humane nursing care and the use of medical interventions only to control distressing symptoms and not merely to prolong my existence

- I consent to the use of analgesics and other measures to control distressing symptoms regardless of the consequences for my physical health I have discussed this document with my general practitioner, Dr Wilma Glass of Any Surgery, Any Town, Tel 01456 654321. I reserve the right to revoke this directive at any time.

Signed:

Date:

Witness signature: I hereby witness the signing of this document by the above named in my presence. She is of sound mind, understands the implications of the document and, to the best of my knowledge, has been brought under no external pressure to sign it. I do not stand to gain from her death.

Signed:

Date:

Copies of this form are with my general practitioner, solicitor, next of kin, and hospital records

documents (box 1). An analysis based on a general discussion of this advance directive has been written up elsewhere. ${ }^{12}$ Participants were then shown a critical care vignette relating to the patient, who had written the advance directive before developing dementia (box 2). They were asked what they believed was the "right thing to do."

All interviews and focus group discussions were recorded on MiniDisc, transcribed verbatim, and analysed according to a modified grounded theory approach. $^{13}$ Preliminary coding categories were derived from the topic guide but were refined to take account of the issues raised by participants, with earlier transcripts being systematically revisited in light of these new categories. ${ }^{14}$ Most of the coding was carried out by TT, but RB and LS independently coded the transcripts of one focus group and one interview, and our various interpretations are compared from the perspectives of clinician, sociologist, and ethicist. ${ }^{15} \mathrm{We}$ analysed data with Atlas.ti. ${ }^{16}$

\section{Results}

\section{To treat or not to treat?}

The vignette was designed to create dissonance between the ethics of beneficence and respecting autonomy. Without the advance directive the patient would be treated:

I think the thing about the will is a complication because if she hadn't written the will I would definitely treat her. (Female general practitioner, mixed group; No 23)

No participant said that they would withhold treatment in the absence of the advance directive. The hypothetical advance directive stated, however, that "with the development of any life threatening medical situation I should not be given active treatment such as antibiotics."

As anticipated, this scenario created division of opinion. Six of the 12 interviewees (three nurses and three doctors) said that they would not treat the patient with antibiotics, whereas five (all doctors) said that they would. The position of one of the interviewees was unclear. Opinion was also equally divided between and within focus groups.

How did the respondents justify their different positions? Before examining this question some important additional factors in the decision making process are presented.

\section{Factors in decision making}

Many thought the right thing to do was to get more information from as many sources as possible. Three of the four interviewees who mentioned the need to try and communicate directly with the patient were nurses. The following is a response to the initial question of the "right thing to do":

\section{Box 2: Hypothetical clinical vignette}

The patient is 78 years old. She lives in a residential home. Up until retirement she worked as a secretary to the headmaster of a private school. She has a devoted daughter who visits twice a week and another daughter "down south" who comes up infrequently.

The patient lives with dementia. She can walk and feed herself and needs some help with dressing. She occasionally wanders at night. Her physical health is good in that she is not currently being treated for any medical condition, having had a thorough assessment at the hospital one year ago.

She recognises her daughter and is glad to see her, but her conversational repertoire is limited-the daughter does virtually all the talking during visits. She is unable to read-something that up until three years ago she did avidly. She is undemanding, popular with the staff, and does not seem to be distressed.

She made an advance statement aged 70 years at a time when she enjoyed good mental and physical health. This was given to the home when she arrived 18 months previously.

One night, after a home outing, she comes down with a high fever. The doctor is called and examination shows that she has a pneumonia. With antibiotic treatment she may make a full recovery, without it there is a significant chance she will die. 
Table 1 Characteristics of participants in focus groups

\begin{tabular}{|c|c|c|c|c|c|c|c|}
\hline Participants & Sex & Age & Job description & $\begin{array}{l}\text { Attitude to advance } \\
\text { directives }\end{array}$ & $\begin{array}{l}\text { Contact with } \\
\text { advance } \\
\text { directives }\end{array}$ & Legal risk* & $\begin{array}{c}\text { Has advance } \\
\text { directive }\end{array}$ \\
\hline \multicolumn{8}{|l|}{ Nurse groupt: } \\
\hline 1 & Female & $41-50$ & Ward manager & Positive & Never & Yes & No \\
\hline 2 & Female & $21-30$ & $\begin{array}{l}\text { Staff nurse (medicine for } \\
\text { elderly people) }\end{array}$ & Neutral & Never & No & No \\
\hline 3 & Female & $31-40$ & Palliative care nurse & Neutral & Once & No & No \\
\hline 4 & Female & $41-50$ & Specialist sisterł & Positive & Never & No & No \\
\hline 5 & Female & $31-40$ & $\begin{array}{l}\text { Staff nurse (medicine for } \\
\text { elderly people) }\end{array}$ & Neutral & Never & No & No \\
\hline 6 & Female & $41-50$ & Ward manager & Positive & Never & No & No \\
\hline \multicolumn{8}{|c|}{$\begin{array}{l}\text { General practitioner } \\
\text { group: }\end{array}$} \\
\hline 7 & Male & $31-40$ & General practitioner & Neutral & Twice & Yes & No \\
\hline 8 & Male & $41-50$ & General practitioner & Neutral & Once & No & No \\
\hline 9 & Female & $41-50$ & General practitioner & Positive & Never & Yes & Yes \\
\hline 10 & Male & $51-60$ & General practitioner & Neutral & Twice & No & No \\
\hline \multicolumn{8}{|c|}{ Consultant group§: } \\
\hline 11 & Male & $41-50$ & Geriatrician & Negative & Never & No & No \\
\hline 12 & Female & $31-40$ & Geriatrician & Neutral & Never & Yes & No \\
\hline 13 & Male & $51-60$ & Geriatrician & Negative & Twice & No & No \\
\hline 14 & Male & $41-50$ & Geriatrician & Positive & Never & Yes & No \\
\hline \multicolumn{8}{|c|}{ Hospice group: } \\
\hline 15 & Male & $31-40$ & Charge nurse & Positive & Never & Yes & No \\
\hline 16 & Male & $51-60$ & Nurse manager & Neutral & Never & No & No \\
\hline 17 & Female & $41-50$ & Social worker & Positive & Never & Yes & No \\
\hline 18 & Female & $31-40$ & Staff nurse & Neutral & Once & Yes & No \\
\hline \multicolumn{8}{|l|}{ Mixed group: } \\
\hline 19 & Male & $41-50$ & Nurse manager & Positive & Never & Yes & No \\
\hline 20 & Female & $41-50$ & Nurse manager & Positive & Twice & No & No \\
\hline 21 & Female & $41-50$ & Nurse manager & Positive & Never & No & No \\
\hline 22 & Female & $31-40$ & Geriatrician & Negative & Never & Yes & No \\
\hline 23 & Female & $41-50$ & General practitioner & Positive & Twice & Yes & No \\
\hline 24 & Female & $41-50$ & Nurse manager & Positive & Twice & Not sure & No \\
\hline 25 & Male & $31-40$ & General practitioner & Neutral & Twice & Yes & No \\
\hline 26 & Female & $31-40$ & Nurse manager & Neutral & Never & Yes & No \\
\hline 27 & Female & $41-50$ & Consultant (hospice) & Positive & Yes & No & No \\
\hline \multicolumn{8}{|c|}{$\begin{array}{l}\text { Specialist registrar } \\
\text { group श: }\end{array}$} \\
\hline 28 & Female & $21-30$ & Specialist registrar & Positive & Never & Yes & No \\
\hline 29 & Female & $21-30$ & Specialist registrar & Neutral & Never & Yes & No \\
\hline 30 & Female & $31-40$ & Specialist registrar & Positive & Never & No & No \\
\hline 31 & Female & $31-40$ & Specialist registrar & Neutral & Never & No & No \\
\hline 32 & Female & $31-40$ & Specialist registrar & Positive & Never & No & No \\
\hline 33 & Male & $21-30$ & Specialist registrar & Neutral & Never & Yes & No \\
\hline 34 & Female & $31-40$ & Specialist registrar & Neutral & Never & Not sure & No \\
\hline
\end{tabular}

${ }^{*}$ Concern about risk of prosecution for not following terms of advance directive.

$\dagger$ All were nurses on staff of teaching hospital.

‡Cares for young people with severe and life shortening chronic illness, including HIV and hepatitis.

$\S$ Department of medicine for elderly people.

ISpecialising in geriatrics.

I think to discuss with [the patient] what her wishes are, to read the advance directive, to speak to both the daughters if possible and to speak to the nursing team, and to read her notes." (Female hospice nurse, interviewee; No 43)

In all 12 interviews, reference was made to the need to engage the family in the discussion. This consideration highlights the limitations of the vignette based approach, where participants' decisions are constrained by limited information-the "it depends" response. ${ }^{17}$ The general practitioners were keen to be able to draw on their knowledge of the patient in sound mind. Another issue was whether or not the patient would require intravenous antibiotics. Some would likely have stopped short of transfer to hospital.

Notwithstanding this missing information, what reasoning did participants put forward to explain their decision making? Those who would treat the patient constructed two main types of argument. Firstly they argued that treatment is wholly consistent with the terms of the advance directive and secondly that to follow the directive would be to go against the best interests of the patient. Withholding treatment was justified primarily on the grounds of respecting autonomy. Box 3 summarises the reasons for and against treatment.

\section{Arguments why treating is consistent with advance} directive

The most commonly presented justification for treatment was that the patient's dementia did not constitute "severe degenerative brain disease." This was put forward by half the interviewees and one in four of the focus group participants: 
Table 2 Characteristics of interviewees

\begin{tabular}{|c|c|c|c|c|c|c|c|}
\hline Interviewee & Sex & Age & Job description & $\begin{array}{l}\text { Attitude to } \\
\text { advance directives }\end{array}$ & $\begin{array}{l}\text { Contact with } \\
\text { advance directives }\end{array}$ & $\begin{array}{l}\text { Legal } \\
\text { risk }^{*}\end{array}$ & $\begin{array}{c}\text { Has advance } \\
\text { directive }\end{array}$ \\
\hline 35 & Male & $51-60$ & General practitioner & Positive & Never & Yes & No \\
\hline 36 & Male & $41-50$ & Surgeon & Neutral & Never & No & No \\
\hline 37 & Female & $41-50$ & General practitioner & ?Negative† & Twice & No & No \\
\hline 38 & Male & $>60$ & Geriatrician (retired) & Negative & Twice & No & No \\
\hline 39 & Female & $41-50$ & General practitioner & Positive & 10 times & No & No \\
\hline 40 & Male & $41-50$ & Anaesthetist & Positive & Never & Yes & No \\
\hline$\overline{41}$ & Female & $>60$ & General practitioner (retired) & Positive & Once & No & Yes \\
\hline$\overline{42}$ & Female & $31-40$ & Nurse (private nursing home) & Positive & Never & No & Yes \\
\hline 43 & Female & $31-40$ & Sister (hospice) & Positive & Six times & Yes & Yes \\
\hline 44 & Male & $31-40$ & Community psychiatric nurse & No opinion & Never & No & No \\
\hline 45 & Female & $41-50$ & Consultant: hospice & Negative & Twice & Yes & No \\
\hline 46 & Female & $41-50$ & Staff nurseł & Positive & 10 times & No & Yes \\
\hline
\end{tabular}

${ }^{*}$ Concern about prosecution for not following advance directive.

†Box left blank, but participant recruited owing to speaking vociferously against advance directives at postgraduate meeting.

$\ddagger$ Department of medicine for elderly people.

It's my clinical judgment that she doesn't have severe degenerative brain disease, that's she's got mild to moderate degenerative brain disease, and therefore the terms of a directive don't qualify. (Male general practitioner, interviewee; No 35)

This is clearly a question of interpretation, with some participants arguing that a condition that renders the patient unable to read or converse should be judged severe, especially in light of its progressive nature. The next most common argument was that the use of antibiotics is justified as a means of symptom control (as opposed to a means of preventing death):

This comes under the idea of humane nursing and care ... because although pneumonia may sometimes be silent in that kind of situation, it quite often isn't. It can be quite unpleasant. (Female general practitioner, interviewee; No 37)

In five interviews and two focus groups the presenting complaint was considered not necessarily life threatening. The patient might survive her untreated pneumonia and be left in a state of ongoing respiratory distress and worsening cognition-the very state that she wanted to avoid in signing the directive:

Very often you're treating not the condition as it is now but the condition as it will be if we don't. (Male geriatrician, retired, interviewee; No 38)

\section{Arguments why advance directive should not be followed}

The preceding arguments are couched as legitimate interpretations of the advance directive. However most of the arguments in favour of treating centre on the view of the patient as having, despite her dementia, a reasonable quality of life that is intrinsically worth preserving regardless of the advance directive:

I'd give her penicillin, I really would, regardless of her living will. I think I can defend that. She is clearly not unhappy in any obvious sense. Her daughter who comes and visits her every week is probably giving her something, who can say? (Male general practitioner, general practitioner group; No 10)

According to this argument, while acknowledging the existence of the advance directive, the carer has a duty to reflect on what the patient would really want to happen to her in this scenario, with the feeling that her current state is not the one she had in mind when drafting it:

Now, I don't mean, wilfully, to reinterpret this in the view of what I want to do ... but, at the same time you have to be sympathetic to what she really meant when she wrote this. (Male surgeon, interviewee; No 36)

This is a matter of individual judgment. Participants were pressed to explain their view that the patient had a reasonable quality of life (box 4). Some participants warned against reliance on such interpretations:

The point is that that's your interpretation. Here we come back to the same problem, "quality of life is not bad." Who says so? The doctors. (Male anaesthetist, interviewee; No 40)

Many participants found it difficult to balancing subjective impressions of the patient's quality of life against her expressed desire for autonomy. This was evidenced by lengthy debates resulting in two focus group participants changing their points of view in the course of discussion. Several of those who thought that the patient's quality of life warranted treatment, discussed how they would use the ambiguity of the advance directive to justify their treatment choices:

I feel in [the patient's] view this is probably the situation where she would want that [the advance directive] enacted. I think as a doctor I could let myself out of this by saying she is not severely demented at all, treat it and then we will ask questions afterwards. (Female specialist registrar, specialist group; No 31)

\section{Arguments for withholding antibiotics}

The primary argument for withholding treatment was respect for autonomy. Those who would not treat argued that the patient had lived a full life and had put thought into how she would like her end to be. She had taken the trouble to draft an advance directive, discussed its contents with a doctor, and distributed it to various parties, including her solicitor. These protagonists argued that she had a severe and irreversible degenerative brain disease, was unable to participate in decisions about her care, had an acute life threatening illness of the type she was thinking of when she wrote her advance directive, and had specifically refused treatment with antibiotics in such a scenario:

Make her comfortable, I mean she made this statement eight years ago when she knew exactly what she wanted ... she can't read anymore, her intellect has gone, I would think that at 70 years old this is what she wouldn't want so ... keep her comfortable. (Female ward manager, nurse group; No 1)

To treat her, they argued, would be in direct contradiction of the patient's clearly expressed wishes. 


\section{Box 3: Factors for and against antibiotic treatment of patient in scenario}

\section{Factors for treatment}

- Treatment as basic clinical instinct:

"One would automatically have treated and it's only the presence of the advance directive that would have made me consider not treating." Female general practitioner, general practitioner group (No 9)

- Not severe degenerative brain disease:

"It says here quite clearly [that the patient] lives with dementia ... that says essentially that she is not suffering from what I would define here as severe degenerative brain disease." Male geriatrician, retired, interviewee (No 38)

- Antibiotics as symptom control:

"With the pneumonia she is breathless, she is struggling, her quality of life isn't actually improving and following the directive you would be able, legitimately, to give her antibiotics." Female palliative care nurse, nurse group (No 3)

- Condition not life threatening:

"Does pneumonia mean a life threatening medical situation? That is open to debate. That's the problem with living wills." Male anaesthetist, interviewee (No 40)

- No treatment will worsen morbidity:

"She may end up in a worst state from this pneumonia, especially if she'd been walking up to a week or so before." Female general practitioner, interviewee (No 37)

- Patient enjoys good quality of life:

"She recognises her daughter, she feeds herself. In the nursing homes where we go, that's not bad." Male general practitioner, general practitioner group (No 8)

- Patient had not envisaged this scenario:

"I think this advance directive says 'don't treat me in this situation, let me die.' But my concern is, does [the patient] at 78 years old really feel that now?" Female specialist registrar, specialist registrar group (No 31)

- Antibiotics are not burdensome:

"In my experience families don't regard an antibiotic therapy as an aggressive intervention." Male nurse manager, mixed group (No 19)

- Unsure if patient is incompetent:

"The fundamental question is, has her intellectual function deteriorated to the state where she's covered by the advance directive?” Male general practitioner, interviewee (No 35)

- Not treating her will upset other patients:

"The residents will say 'Oh this is something that's happening now. If we get a cold we're not going to get treated anymore." Female general practitioner, interviewee (No 39)

- Advance directive is out of date:

"I would have some concerns. In eight years a lot of things may have changed." Male anaesthetist, interviewee (No 40)

\section{Against treatment}

- Autonomy should be respected:

"I'm going with the choices of the patient expressed in the living will, her last expressed wish and respecting her right to autonomy." Female hospice nurse, interviewee (No 43)

- Patient would not want treatment:

"This isn't the [person] she wants to be. She's obviously thought it through and this is her 'out'." Female staff nurse, interviewee (No 46)

- Patient has severe degenerative brain disease:

"With Alzheimer's you can no longer converse or read a book, is that not severe? I think that is severe degenerative

brain disease." Female nurse manager, nurse group (No 1)

- Dementia will worsen:

"Her dementia's going to get worse. She could wander out and get killed or raped or mugged, or anything"

Female nurse in geriatrics, interviewee (No 46)

- Unable to participate in decisions:

"In a lady who is demented, who cannot make decisions, it's quite clear she cannot make decisions ..."

Male anaesthetist, interviewee (No 40)

- Has specifically refused antibiotics:

"She has made this will out to say that if she is suffering from Alzheimer's she doesn't want any antibiotics." Female

staff nurse, nurse group (No 5)

- Current quality of life is poor:

"She can make no decisions for herself at all. She doesn't even initiate conversation when her daughter is there." Female ward manager, nurse group (No 6)

- Antibiotics will necessitate transfer:

Researcher: "Can you ever have patients on intravenous drugs here?"

Interviewee: "No, this is a nursing home and we don't do that." Female nurse, private nursing home, interviewee (No 42)

Furthermore, any argument for treatment based on a lay or professional carer's perception that she was "happily demented" could be seen as no more than the projection of one person's set of values on another. Even if her dementia were not far advanced, it inevitably would become so. It was the patient's wish to avoid interventions at this stage so that she might be spared the indignity of further decline into imbecility. Thus, to treat her was to consign her to a future she had hoped to avoid. This line of thinking depended on the pneumonia being life threatening: non-treatment might have the reverse of the intended effect. 
Legal implications of decision making in scenario In the United Kingdom there is no statutory law relating to advance directives, although such laws do exist in several countries. UK case law has established guidance for the creation of advance directives, but the obligation of doctors to follow them has not yet been tested in the courts. ${ }^{18}$ Several participants were boldly dismissive of the legal status of the advance directive:

It has none, no status at all. (Female general practitioner, interviewee; No 39)

Others expressed uncertainty. All those who would treat the patient thought they could justify their decisions with reference to the ambiguities. Although four participants cited the potential value of advance directives in offering legal protection to the doctor who went against a family by withholding treatment, only one participant was in favour of statutory legislation. The following is from a participant who was positive about advance directives:

I think that the medicine and the law are very uneasy bedfellows. I think that [legislation] would be a most retrograde step simply because the law is about certainties and medicine is very much about uncertainties. (Male general practitioner, interviewee; No 35)

\section{Discussion}

Decisions made by health professionals about the "right thing to do" when confronted with a hypothetical advance directive applied to a hypothetical critical care vignette varied widely. Five of 12 interviewees favoured antibiotic treatment for the patient's lobar pneumonia whereas six opposed it. Participants differed in their interpretation of ambiguous phrases such as "severe degenerative disease" and "life threatening" and the question of whether antibiotic treatment was palliative and therefore allowable under the terms of the advance directive. Those who favoured treatment tended to see adherence to the advance directive as not being in the patient's best interests, whereas those who opposed treatment invoked respect for autonomy as the determining ethical principle. Those who favoured treatment were particularly swayed by subjective judgments on the quality of life of the "happily demented" patient.

Most of the participants came from greater Glasgow, and it is possible that the findings were influenced by regional culture. Given the sampling methods, it is unlikely that these participants were representative of UK health professionals. However, the attitudes expressed were broadly consistent with those from a 1997 survey of general practitioners in the West of Scotland. ${ }^{19}$ The findings relate to a specially constructed advance directive and cannot be directly transferred to any of those currently in regular use. The clinical vignette was an effective stimulus to discussion and allowed a comparison of decision making between participants. But the vignette offers only an approximation of the multifactorial arena of decision making in the real world, in which input from staff and relatives and previous knowledge of the patient all play a part in influencing professionals' actions.

We conclude that advance directives are open to different interpretations and that anyone creating one cannot assume that any particular outcome will result from its implementation. Outcome depends to a great
Box 4: Reasons why patient was considered to have a reasonable quality of life (all quoted respondents favoured antibiotic treatment)

- Physically fit

- Walks about

- Able to dress herself

- Able to feed herself, which is complicated

- Can do quite a bit for herself

- Has a daughter who visits

- Gets on with her daughter

- Recognises her daughter

- Was taken out on a day trip

- Still able to enjoy a day trip

- Can smile

- Life still has some meaning

- Not screaming her head off

- Not pacing up and down all night

- Not doubly incontinent

- Appears contented and happy

- Not unhappy in any obvious sense

- Mild end of the dementia spectrum

extent on who deals with the advance directive. This is the sort of reasoning that lies behind the drive for legislation to make advance directives binding on health professions - a move recently rejected in the United Kingdom by the House of Lords. ${ }^{20}$ However, given the ambiguous nature of terminology used in advance directives, it seems unlikely that successful prosecution could proceed, with the legal profession trying to interpret terms such as "life threatening," "irreversible," and "futile."

One weakness of advance directives of this sort is that they give little information about what in the patient's view constitutes a good quality of life. Such information might make decisions faced by health professionals easier. Increasing attention has been applied to the use of "values histories" for this purpose. ${ }^{21}$ They identify "core values and beliefs in the context of terminal care that are important to the patient." They might, for instance, place a premium on remaining at home or on "buying time" so that distant loved ones can visit.

Our study emphasises the central role for clinical judgment in critical care decision making. ${ }^{22}$ Advance directives will not lessen the responsibility of health professionals to weigh up a range of conflicting considerations. In so doing they should seek to synthesise their scientific knowledge with an appreciation of the patient's individual predicament. Arguably what some of the participants lacked was a willingness to step outside their own values systems in fully embracing that of the patient. Medical education should seek to development students' empathic skills, and scenarios such as this could be used for this purpose. $^{23}$

As seems to be the case with lay carers, advance directives may have limited ability to influence decision making by health professionals on end of life, although they may exert other important benefits by opening dialogue and conferring peace of mind. ${ }^{84}$

We thank the participants for their time and contributions and Debbie Sharp for help with the manuscript. 


\section{What is already known on this topic}

Advance directives are written statements made by patients about future treatment preferences if they are mentally incapable of expressing them

Little is known about how health professionals react to the presence of an advance directive in a critical care situation

\section{What this study adds}

Health professionals come to different conclusions about the "right thing to do" when applying the terms of an advance directive to a clinical scenario

Some health professionals are willing to over-rule the preferences stated on the grounds of beneficence

Variations in interpretation are explained in part by the ambiguity of advance directive terminology and the situations in which they are applied

This same ambiguity would make legislation, compelling doctors to adhere to advance directives, difficult to enforce

Contributors: TT had the original idea for the study, collected the data, and was responsible for the overall running of the project; he will act as guarantor for the paper. RB was the research supervisor and was intimately involved in all stages of design and analysis. LS was involved in the design of the study and was particularly responsible for advice on ethical concepts. All authors contributed to the writing of the manuscript.

Funding: The empirical work for this paper was undertaken while TT, RB, and LS were based at the Department of General Practice, University of Glasgow, and TT was funded by the Scottish Office as a higher professional training fellow. This study was supported by a grant from the Scientific Board of the Royal College of General Practitioners. The guarantor accepts full responsibility for the conduct of the study, had access to the data, and controlled the decision to publish.

Competing interests: None declared.

Ethical approval: At the time the study was carried out (November 1999 to February 2000) it was not a formal requirement to obtain ethical approval for non-interventional research with health professionals. All participants gave signed consent.

1 British Medical Association. Withholding and withdrawing life-prolonging treatment. Guidance for decision making. London: BMJ Publishing, 1999.

2 Charles C, Whelan T, Gafni A. What do we mean by partnership in making decisions about treatment? BMJ 1999;319:780-2.

3 Downie RS, Calman KC. Healthy respect. Oxford: Oxford University Press, 1994:51.

4 Neuberger J. Dying well: a guide to enabling a good death. Hale, Cheshire: Hochland and Hochland, 1999.

5 Ikonomidis S, Singer P. Autonomy, liberalism and advance care planning. J Med Ethics 1999;25:522-7.

6 Sommerville A. Remembrance of conversations past: oral advance statements about medical treatment. BMJ 1995;310:1663-5.

7 Danis M, Southerland LI, Garrett JM, Smith JL, Hielema F, Pickard CG, et al. A prospective study of advance directives for life-sustaining care. N Engl J Med 1991;324:882-8.

8 Ditto PH, Danks JH, Smucker WD, Bookwala J, Coppola KM, Dresser R, et al. Advance directives as acts of communication: a randomized controlled trial. Arch Intern Med 2001;161:421-30.

9 Davidson KW, Hackler C, Caradine DR, McCord RS. Physicians' attitudes on advance directives. JAMA 1989;262:2415-9.

10 Kelner M, Bourgeault IL, Hebert PC, Dunn EV. Advance directives: the views of health care professionals. CMAJ 1993;148:1331-8.

11 Mallik M. Advocacy in nursing-a review of the literature. I Adv Nurs 1997;25:130-8.

12 Thompson TDB, Barbour RS, Schwartz L. Health professionals' views on advance directives - a qualitative interdisciplinary study. Palliat Med 2003;17:403-9.

13 Barbour RS. Acquiring qualitative skills for primary care research. Review and reflections on a three-stage workshop. Part 2: analysing interview data. Members of WoReN. Primary Care Research Network. Fam Pract 2000;17:83-9.

14 Ritchie J, Spencer L. Qualitative data analysis for applied policy research. In: Bryman A, Burgess RG, ed. Analyzing qualitative data. London: In: Bryman A, Burges
Routledge, 1994:173-94.

15 Barbour RS. Checklists for improving rigour in qualitative research: a case of the tail wagging the dog? BMJ 2001;322:1115-7.

16 Muhr T. ATLAS/ti Short user's guide. Berlin: Scientific Software Development, 1997.

17 Downie RS, Calman KC. Healthy respect. Oxford: Oxford University Press, 1994:141.

18 McLean S. Advance directives: legal and ethical considerations. In: Pace $\mathrm{N}$, McLean S, ed. Ethics and the law in intensive care. Oxford: Oxford University Press, 2000:68-83.

19 Collins K, Lightbody P, Gilhooly M. Living wills: a survey of the attitudes of general practitioners in Scotland. Br J Gen Pract 1999;49:641-2.

20 House of Lords. Report of the select committee on medical ethics. Vol 1. Report. London: HMSO, 1994:54, para 264. (HL paper 21.1.)

21 Docker C. Decisions to withdraw treatment. Values histories are more useful than advance directives. BMJ 2000;320:54.

22 Downie RS, Macnaughton J. Clinical judgement. Oxford: Oxford University Press, 2000.

23 Hojat M, Mangione S, Gonnella JS, Nasca T, Veloski JJ, Kane G. Empathy in medical education and patient care. Acad Med 2001;76:669.

24 Swartz R, Perry E. Advance directives in end-stage renal disease inherently involve family and staff. Adv Ren Replace Ther 1998;5:109-19.

(Accepted 4 September 2003) 